Modifier la structure des pâtes par la formulation et le procédé influence t'il leur métabolisme? 出

Does the structural modification of pasta by formulation and process change its metabolism? Karima Laleg1,2, Valérie Greffeuille² Stéphane Walrand1, Valérie Micard²*

${ }^{1}$ CRNH Auvergne, UNH, UMR 1019, Inra, F-63000, Clermont-Ferrand, France.

2 UMR IATE 1208, Cirad, Inra, Montpellier SupAgro, Université de Montpellier, F-34060 Montpellier, France;

\title{
Laboratoires :
}

UMR 1019, 58 rue Montalembert - BP 321, 63009 Clermont-Ferrand

UMR 1208, 2 Place Pierre Viala - 34060 Montpellier

Centre Hospitalier Régional Universitaire Lapeyronie- Plateforme ApaNut, Montpellier, France

* Contact : Valérie Micard

Tél. : +33 (0)4 99612889

UMR 1208, 2 Place Pierre Viala - 34060 Montpellier

e-mail : valerie.micard@supagro.fr

it article ayant fait l'objet d'une conférence lors des JFN2017 


\section{Introduction}

Les pâtes alimentaires sont consommées dans le monde entier. Elles constituent, avec le couscous, un des principaux débouchés de la filière blé dur, avec environ $75 \%$ de la semoule produite en France destinée à leur production. L'Union Européenne est le premier producteur de pâtes alimentaires dans le monde avec 5 millions de tonnes produites en 2016 soit plus d'un tiers de la production mondiale (1). La production Française de pâte s'élevait à 230651 tonnes en 2017, pour une consommation de 527276 tonnes, nécessitant l'importation de 64\% des pâtes consommées, principalement d'Italie (2).

Les pâtes alimentaires ont également d'intéressantes qualités nutritionnelles, liées à leur composition (semoule de blé) et à leur structure construite au cours des étapes successives (hydratation-malaxage, extrusion, séchage, cuisson) du procédé de pastification. La structure spécifique des pâtes se caractérise par la présence d'un réseau dense de protéines encapsulant les granules d'amidon $(3,4)$ limitant ainsi leur gonflement et leur susceptibilité à l'hydrolyse enzymatique $(5,6)$. Elle confère aux pâtes leur faible indice glycémique (IG ; autour de 32-65) (7) en faisant ainsi un aliment d'intérêt. La consommation d'aliments à faible indice glycémique serait en effet associée à une moindre prévalence de pathologies comme le diabète, les maladies cardio-vasculaires et certains cancers $(8,9)$, et participerait au contrôle du poids et à la prise en charge de l'obésité par une action sur la satiété, le rassasiement et la $\beta$-oxydation des lipides invivo (10).

Outre sa richesse en amidon $(\sim 72 \%)$ et son faible IG, la pâte alimentaire est également une source non négligeable de protéines $(\sim 12 \%)$, mais ces dernières sont pauvres en certains acides aminés indispensables, comme la lysine et la thréonine (11). De plus, comme tout aliment contenant du gluten, la pâte peut provoquer des réactions allergiques ou des intolérances plus ou moins sévères chez certains individus. Pour ces populations, d'autres ingrédients pouvant se substituer partiellement ou intégralement aux protéines de gluten dans les pâtes doivent être recherchés. Les légumineuses, riches en protéines (entre 20 et 40\%) (12) dont les acides aminés indispensables sont complémentaires à ceux du blé (lysine et thréonine), constituent une source d'intérêt. Utilisées en mélange avec le blé, elles peuvent permettre la production de spécialités pastières enrichies en protéines et équilibrées en acides aminés indispensables $(13,14)$. Totalement Substituées à la semoule de blé dans les pâtes, elles pourraient également convenir aux personnes allergiques au gluten ou souffrant de la maladie coeliaque.

L'incorporation de légumineuse dans une pâte alimentaire, si elle semble intéressante sur le plan nutritionnel, pose au-delà d'un certain pourcentage $(\sim 30 \%)$ de farines de légumineuses des problèmes techniques au moment de la pastification $(13,15)$. Elle change également la structure finale de la pâte altérant de fait leur texture et leurs qualités culinaires (16-18). La modification de certains paramètres du procédé de fabrication des pâtes, telles que les températures de séchage, peut prévenir une telle altération (13). Néanmoins, ces changements de paramètres du procédé pourraient, au même titre que le changement de formulation consistant à incorporer des légumineuses, modifier la structure de la pâte et affecter positivement ou négativement la digestibilité de ses principaux nutriments, l'amidon et les protéines. Une augmentation des températures de séchage de $20^{\circ} \mathrm{C}$ à $180^{\circ} \mathrm{C}$ entraine ainsi une augmentation du taux de protéines indigestibles de $110 \%$ dans les pâtes alimentaires (19) liées à une forte agrégation des protéines par interactions hydrophobes et covalentes. L'utilisation de conditions drastiques de séchage 
$\left(90^{\circ} \mathrm{C}\right.$ à faible humidité des pâtes) de pâtes enrichies avec $35 \%$ de farines de légumineuses (pois cassé ou fève) entraine elle une réduction du taux de glucose rapidement digestible de $21 \%$ en comparaison avec un séchage moins intense $\left(55^{\circ} \mathrm{C}\right)(20)$.

L'objectif de cet article est d'éclaircir l'effet de la modification de la structure des pâtes alimentaires consécutive à un changement de leur formulation (enrichissement en légumineuses) et de leur procédé de fabrication (température de séchage) sur la digestion invitro des protéines et de l'amidon et sur leur utilisation métabolique in-vivo sur modèles rats et sur volontaires humains.

\section{Matériel et méthodes}

\section{Matières premières}

La semoule de blé dur (BD) et la poudre de gluten ont été fournies respectivement par Panzani (Semoulerie de Bellevue, Marseille, France) et par Syral (Aalst, Belgique). La farine de fèverole (F) a été fournie par GEMEF (Aix-en-Provence, France). La composition des matières premières a été déterminée et est présentée dans le Tableau 1. Les protéines ont été analysées par la méthode de Kjeldhal (NF V 03-050, 1970), avec un coefficient de conversion de 6.25 pour les protéines de légumineuses et 5.7 pour les protéines de blé. Le contenu en amidon a été déterminé en utilisant un kit enzymatique (Megazyme, Co. Wicklow, Ireland; méthode AACC 7613.01). Les fibres totales ont été déterminées par l'ISHA (Lonjumeau, France), en utilisant la méthode JORF (1986) (21). Les lipides ont été déterminés par Inovalys (Nantes, France) selon la norme NF ISO 6492 et NF-EN-ISO 12966-2.

Tableau 1 Composition des matières premières

\begin{tabular}{ccc}
\hline $\begin{array}{c}\text { Composition } \\
\text { (\% matière sèche) }\end{array}$ & F & BD \\
\hline Amidon & 57,6 & 77,8 \\
Fibres totales & 11,7 & 2,4 \\
Protéines & 24,0 & 13,1 \\
Lipides totaux & 1,9 & 2,3 \\
\hline
\end{tabular}

F, fèverole ; BD, blé dur.

\section{Production des pâtes}

Les pâtes ont été produites au sein de l'unité mixte de recherche UMR IATE-Montpellier. Des pâtes contenant des ratios «blé dur / fèverole » $(\mathrm{BD} / \mathrm{F})$ de «100/0 » (100\% BD), «65/35 » $(35 \% \mathrm{~F}), \ll 30 / 70 »(70 \% \mathrm{~F})$ et « $0 / 100 »(100 \% \mathrm{~F})$ ont été produites en mélangeant les quantités nécessaires de semoule de blé et de farine de fèverole. Une autre pâte $100 \%$ blé isoprotéique par rapport à la pâte $35 \%$ fèverole (soit à $17 \%$ protéine) a également été produite par ajout de $6 \%$ de poudre de gluten à la semoule de blé dur. Cette pâte est utilisée comme témoin pour l'étude in-vivo. La transformation des mélanges en spaghetti a été réalisée comme décrit par Petitot et al. (13) pour la pâtes $100 \%$ BD et 35\% F. Les pâtes 70\% F et 100\% F ont été produites selon le 
brevet W02016097328 A1 (22), en utilisant une presse à pâte Bassano (Lyon, France). Les spaghettis frais ont été séchés (AFREM, Lyon, France) à basse température (BT) ou à très haute température (THT) comme indiqué dans la figure 1. Toutes les pâtes produites ont été cuites selon la méthode AACC (66-50) dans l'eau bouillante, déminéralisée et salée (7 g/L) jusqu'à la gélatinisation totale de l'amidon qui correspond à la disparition de la ligne blanche lors de l'écrasement de la pâte entre deux plaques de plexiglass. Les pâtes sèches et cuites ont fait l'objet d'une détermination de leur teneur en protéines selon la méthode de Kjeldhal (en utilisant un coefficient de conversion d'azote de 5.7 pour les protéines de blé et 6.25 pour les protéines de fèverole) et de leur profil en acides aminés indispensables selon la méthode CEE 152/2009 (2009, Agrobio, Rennes, France).

Figure 1 : Diagrammes de séchage des pâtes.

BT : Basse température, THT : Très haute température, HR\% : Humidité relative

\section{Propriétés culinaires et rhéologiques des pâtes}

Les pertes à la cuisson ont été déterminées sur chacune des pâtes comme la différence entre la masse sèche des pâtes cuites et séchées, exprimée en pourcentage de la pâte sèche.

La résilience des pâtes a été déterminée à l'aide d'un texturomètre (TAXTplus, Stable Micro Systems). Elle représente la capacité d'un brin de spaghetti à reprendre sa forme originale après compression. Le test consiste à appliquer une déformation de $30 \%$ sur un morceau de spaghetti cuit à l'aide d'un module carré (Stable Micro Systems). La courbe "Force en fonction du Temps" obtenue a la forme d'un pic. La résilience est calculée comme l'aire de la seconde moitié du pic sur l'aire de la première moitié du pic.

\section{Agrégation des protéines des pâtes cuites}

L'état d'agrégation des protéines dans les pâtes cuites lyophilisées broyées a été suivi par chromatographie liquide haute performance d'exclusion stérique (SE-HPLC) après extraction selon la méthode de Morel et al. (23). Une première extraction conduite à $60^{\circ} \mathrm{C}$ pendant $80 \mathrm{~min}$, sous agitation rotative, dans du tampon phosphate $(0,1 \mathrm{M}, \mathrm{pH} 6.9)$ contenant $1 \%$ de SDS, permet d'extraire la fraction des protéines liées par des interactions faibles. Une seconde extraction réalisée à $60^{\circ} \mathrm{C}$ pendant $60 \mathrm{~min}$ dans du tampon phosphate SDS contenant $20 \mathrm{mM}$ de dithioerythritol (DTE) avec sonification pendant $5 \mathrm{~min}$ a permis d'extraire la fraction des protéines insolubles dans le SDS. Cette fraction protéique correspond aux protéines liées par des interactions covalentes de type disulfures. La fraction de protéines restant insolubles après les deux extractions successives constitue la fraction de protéines liées par des interactions covalentes autres que les ponts disulfures. Le pourcentage de protéines dans chacune des fractions a été exprimé en pourcentage du total des protéines dans le mélange de matières premières.

\section{Microscopie en lumière claire des pâtes cuites}

Des coupes transversales de pâtes de $8 \mu$ m ont été réalisées au moyen d'un microtome (Microm HM 520, Walldorf, Germany). Sur ces coupes, les protéines ont été colorées 10 min avec du Fast Green 1 g.L $\mathrm{L}^{-1}$ (Sigma Aldrich Co., USA) et les granules d'amidon avec de l'iode par application d'une solution de Lugol (Fluka, Buchs, Suisse), diluée au 1/8 (v/v). Les coupes ont 
ensuite été rincées à l'eau distillée (3 fois/ 2 min). Les protéines apparaissent ainsi colorées en vert et les granules d'amidon en bleu-violet. Les images ont été observées au moyen d'un microscope AZ100M (Nikon, Japan) équipé d'une caméra Nikon DSRiI (Nikon, Japan).

\section{Digestibilité in-vitro des pâtes}

\section{1. $\quad$ Digestibilité in-vitro des protéines}

La digestibilité des protéines a été réalisée sur $60 \mathrm{mg}$ de pâte cuite lyophylisée et broyée dans un bain marie $\left(37^{\circ} \mathrm{C}\right)$ avec agitation selon la méthode de Pasini et al. (24). Chaque échantillon de pâte a été d'abord digéré par de la pepsine (P7125, Sigma, St. Louis, US ; 73400 U/g de protéines de pâtes, $4 \mathrm{ml}$ de solution à $0,2 \mathrm{~mol} / \mathrm{L} \mathrm{HCl}, \mathrm{pH} 2.2$ ) pendant $30 \mathrm{~min}$ puis par la pancréatine (P7545, Sigma, St. Lois, US ; ajoutée dans 1,5 ml d'acide borique $\mathrm{pH}$ 6,8). La digestion a été arrêtée à la fin de la digestion pancréatique par ajout d'un volume d'acide trichloracétique (1.2 mol/L). la différence entre le taux des groupements amino libre $\left(\mathrm{NH}_{2}\right)$ dans le surnageant au temps T0 et à la fin de la digestion a été mesurée en utilisant la méthode de la ninhydrine (25), et rapportée au $\mathrm{NH}_{2}$ total (issus de l'hydrolyse dans de l'HCL $6 \mathrm{~mol} / \mathrm{L}$, pendant $24 \mathrm{~h}$ à $105^{\circ} \mathrm{C}$ ).

\subsection{Digestibilité in-vitro de L’amidon}

Les analyses de digestibilité in-vitro de l'amidon des pâtes cuites ont été réalisées par Englyst. Carbohydrates Ltd (26). La méthode est basée sur la mesure par chromatographie liquide haute performance de la quantité de glucose libérée par des enzymes digestives durant un temps d'incubation donné, dans des conditions standardisées. Le glucose libéré après $20 \mathrm{~min}$ d'incubation correspond au glucose rapidement disponible (GRD). Il a été exprimé en g pour 100 g de glucides disponibles. Il a été démontré que ce paramètre est corrélé à l'indice glycémique invivo (26). L'amidon digéré entre 20 et 120 min correspond à l'amidon lentement digestible (GLD), et l'amidon non digéré après 120 min de digestion représente l'amidon résistant.

\section{Digestibilité in-vivo des pâtes}

\subsection{Métabolisme protéique}

L'expérimentation animale a été approuvée par le Comité d'Ethique en Matière d'Expérimentation Animale Auvergne: CEMEAA; Permis numéro: C2EA-02. Elle est également conduite en accord avec la règlementation Européenne pour le soin et l'utilisation des animaux de laboratoire (2010-63UE). Les animaux ont été logés au sein de l'animalerie de l'UNH (autorisation $n^{\circ}$ : C6334514). Tous les efforts ont été déployés afin de minimiser la souffrance des animaux.

Six groupes de rats Wistar, mâles âgés d'un mois ont été fournis par JANVIER (Le Genest St Isle, France). Ces rats ont été nourris par un des 6 régimes suivants :

- Régime à base de pâtes enrichies avec 35\% de farine de fèverole séchées à basse température (35\% FBT) ou à très haute température (35\% FTHT). Ces pâtes contiennent $17 \%$ de protéines (calculée sur la base de la composition en protéines des matières premières).

- Régime à base de pâtes de blé, isoprotéiques par rapport aux pâtes contenant $35 \%$ de fèveroles (17\% protéines), produites par ajout de $6 \%$ de poudre de gluten à la semoule de blé dur. Ces pâtes ont également été séchées soit à basse température 100\% BDBT, ou à très haute température (100\% BDTHT).

- Régime à base d'une protéine animale de référence, la caséine, dit contrôle standard (Cs) 
- Régime protéinoprive (Pp), ce régime est utilisé pour mesurer l'azote endogène produit et excrété par les animaux (pertes azotées basales).

Chaque groupe était constitué de 10 animaux sauf le groupe protéinoprivé (14 rats). Chaque régime à l'étude était confectionné en mélangeant aux pâtes la quantité nécessaire de vitamines et minéraux, d'amidon, de cellulose ou de lipides de soja afin d'aboutir à la même valeur énergétique et protéique dans tous les régimes (tableau 2). Tous les régimes ont fait l'objet d'une détermination de leur teneur en amidon (kit enzymatique, Megazyme, Co. Wicklow, Ireland ; méthode AACC 76-13.01), de leur teneur en fibres totales (AOAC, 1990, Qualitech, Arzacq, France) et de leur teneur en lipides (JORF,1977, Qualitech, Arzacq, France) (27). Cette composition a été utilisée pour la détermination de la valeur énergétique des régimes, en utilisant des estimations caloriques de 9,4 et $4 \mathrm{kcal} / \mathrm{g}$ respectivement pour les lipides, les protéines et l'amidon et les fibres.

Tableau 2 : Valeur nutritionnelle et composition en acides aminés indispensables des régimes à l'étude (28)

\begin{tabular}{ccccccc}
\hline Valeur nutritionnelle & $35 \%$ FBT & $35 \%$ FTHT & 100\% BDBT & $100 \%$ BDTHT & Cs & Pp \\
\hline Protéines & 14,1 & 14,2 & 14,1 & 14,0 & 14,1 & 0,2 \\
Amidon & 57,1 & 56,7 & 57,2 & 58,6 & 58,4 & 72,2 \\
Fibres & 6,6 & 5,2 & 4,6 & 2,8 & 6,6 & 5,7 \\
Lipides & 5,3 & 5,8 & 5,5 & 5,0 & 5,3 & 5,7 \\
Energie (kcal/100 g) & 359 & 357 & 353 & 346 & 364 & 364 \\
\hline Composition en AA indispensables (mg/g de protéine) & & & \\
\hline Histidine & 25,8 & 25,4 & 21,9 & 21,8 & 26,4 & \\
Isoleucine & 39,2 & 39,9 & 36,5 & 37,3 & 48,9 \\
Leucine & 78,4 & 80,0 & 73,6 & 72,6 & 88,4 & \\
Valine & 46,9 & 48,0 & 39,9 & 40,7 & 66,5 & \\
Lysine & 37,4 & 35,9 & 19,0 & 17,9 & 75,5 & \\
Sulfur-AA & 32,1 & 31,7 & 43,8 & 44,0 & 46,1 & \\
Aromatic-AA & 77,4 & 77,2 & 75,4 & 76,2 & 88,9 & \\
Threonine & 33,1 & 33,7 & 26,9 & 26,4 & 39,8 & \\
Tryptophan & 11,4 & 10,6 & 10,9 & 9,1 & N/A & \\
Branched AA & 164,5 & 167,9 & 150,0 & 150,6 & 203,8 & \\
\hline
\end{tabular}

35\% FBT et 35\% FTHT, pâtes enrichies avec 35\% de fèverole séchées respectivement à basse température et à très haute température; 100\% BDBT et 100\% BDTHT, pâtes de blé séchées respectivement à basse température et à très haute température; Cs, contrôle standard (caséine) ; $P p$, régime protéinoprivé ; $A A$, acide aminé.

Protéines: $S D<0.2$, amidon: $S D<1$, fibres: $S D<1.8$, lipides: $S D<0.2$.

$N / A$, non analysé.

L'étude a duré 21 jours durant lesquels les rats ont été nourris avec l'un des 6 régimes. La prise alimentaire a été contrôlée chaque semaine. Pendant les 4 derniers jours, les rats ont été transférés en cages métaboliques permettant la mesure de leur prise alimentaire et la récupération de leurs urines et de leurs matières fécales. L'azote a été déterminé en triplicat sur ces échantillons d'urine et de fèces en utilisant la méthode de Dumas et a servi à la détermination de la digestibilité azotée vraie (DV, quantité de protéines absorbées) et de 
l'utilisation nette des protéines (UNP, pourcentage de protéines ingérées retenues). Les formules suivantes ont été utilisées :

- $\quad D V(\%)=\frac{\text { Azote ingéré- }(\text { azote fécal-azote fécal endogène })}{\text { Azote ingéré }} \times 100$
- $\quad U N P(\%)=\frac{\text { Azote ingéré }-(\text { azote fécal }+ \text { azote urinaire })+\text { azote fécal endogène+azote urinaire endogène }}{\text { Azote ingéré }} \times 100$

\subsection{Indice glycémique}

Cette étude ( ${ }^{\circ}$ 2010-A00671-38), décrite en détail dans la publication Greffeuille et al.(29), a été conduite sur des volontaires humains, conformément à la déclaration d'Helsinki, selon la loi française et approuvée par le Comité central d'éthique Sud Méditerranée III (Nîmes), France. L'étude s'est déroulée au CHU Lapeyronie de Montpellier (Service Endocrinologie-DiabétologieNutrition). Les analyses biologiques ont été réalisées au laboratoire de Biochimie et médecine nucléaire du même hôpital. 15 volontaires sains ont participé (8 hommes/7 femmes; âge moyen : $24 \pm 2,9$ ans ; BMI : $22,4 \pm 1,8 \mathrm{~kg} / \mathrm{m}^{2}$ ). Tous les volontaires ont donné leur consentement éclairé écrit.

Les volontaires ont ingéré des quantités correspondant à $50 \mathrm{~g}$ de glucides disponibles de chacune des 3 pâtes cuites 100\% BDBT, 35\% FBT et 35\% FTHT (vs le témoin glucose 50g/250 $\mathrm{ml}$ eau ; période wash out : 1 semaine). La glycémie a été mesurée en utilisant un glucomètre (Accu-Chek ${ }^{\circledR}$ Performa, Roche Diagnostics) après piqure du doigt aux temps $0,5,10,15,30,45$, 60, 90 et 120 min après la consommation de l'aliment. L'indice glycémique (IG) des pâtes a été calculé pour chaque sujet comme l'aire sous la courbe du glucose sanguin durant 120 min, exprimé en pourcentage de la surface de la courbe de réponse au glucose sanguin obtenue avec le témoin (solution de glucose $=100$ ).

\section{Résultats et discussion}

\section{Modulation de la composition et de la structure de la pâte par la formulation}

La composition et la structure de la pâte peuvent être modulées par la formulation, notamment par l'incorporation d'une farine de légumineuse dans la semoule de blé dur. Nous avons analysé la composition et la structure de ces pâtes enrichies en légumineuse en appliquant un même séchage à basse température $\left(55^{\circ} \mathrm{C}-\mathrm{BT}\right)$.

\subsection{L'enrichissement en légumineuses: un moyen efficace pour améliorer la composition en protéines et en acides aminés indispensables des pâtes alimentaires}

L'enrichissement à un taux croissant d'une pâte de blé dur en farine de légumineuses induit une augmentation considérable de sa teneur en protéines. La quantité totale de protéines peut ainsi atteindre $24 \%$ de protéines, pour une pâte $100 \%$ farine de fèverole soit le double d'une pâte $100 \%$ blé (13\% de protéines)(figure 2 ).

La teneur en lysine, acide aminé indispensable, est déficitaire dans la pâte au blé, dans laquelle elle ne satisfait que $46 \%$ des besoins d'un sujet adulte (selon les recommandations de l'ANSES (30)-ex. Afssa) (figure 2). Ce score en lysine augmente au fur et à mesure de l'enrichissement de la pâte en farine de fèverole pour atteindre $145 \%$ des besoins dans une pâte $100 \%$ fèverole. A 
l'inverse, la teneur en acides aminés soufrés indispensables régresse dans le même intervalle, ce score passant de 131 à $76 \%$ des besoins. La composition en acides aminés d'une pâte alimentaire contenant de 35 à $70 \%$ de légumineuses est donc plus équilibrée, au regard des recommandations de l'ANSES, qu'une pâte au blé dur classique et sa teneur en protéines est de 1,3 à 1,6 fois plus élevée. Une pâte contenant autour de $50 \%$ de farine de fèverole pourrait ainsi couvrir $100 \%$ des besoins en lysine et en acides aminés soufrés chez l’Homme.

\section{Figure 2 : Evolution de la teneur en protéines et du score en acides aminés indispensables d'une pâte sèche en fonction de son enrichissement en farine de fèverole.}

Le score en acides aminés indispensables est calculé en rapportant la teneur en acides aminés de l'aliment par rapport aux recommandations de l'ANSES (2007) pour les adultes : lysine : $45 \mathrm{mg} / \mathrm{g}$ de protéines; Acides aminés soufrés : $23 \mathrm{mg} / \mathrm{g}$ de protéines et leucine : $59 \mathrm{mg} / \mathrm{g}$ de protéines. La composition en protéines a été mesurée par le méthode de Kjeldahl (ms = masse sèche)

En ce qui concerne la leucine, sa teneur dans les pâtes augmente également au fur et mesure de l'enrichissement en fèverole jusqu'à atteindre $130 \%$ des besoins à $100 \%$ d'enrichissement en fèverole. Cet acide aminé indispensable joue un rôle majeur dans la stimulation de la synthèse protéique musculaire (31), et son optimisation dans l'alimentation est requise notamment chez les personnes âgées. En effet, avec l'âge, la stimulation de la synthèse protéique musculaire durant la période postprandiale est réduite en relation avec la diminution de l'effet stimulant des acides aminés alimentaires. Néanmoins, une supplémentation en leucine chez les rats âgés ou chez des humains âgés aide à rétablir un anabolisme protéique de la phase postprandiale similaire au modèle adulte $(32,33)$. Le taux relativement plus important en leucine des pâtes enrichies en légumineuses couplé à la quantité plus importante de protéines équilibrées en acides aminés indispensables au sein de ces pâtes mixtes, pourrait être intéressants au cours de certaines situations qui nécessitent un apport important de protéines de bonne qualité alimentaire, comme par exemple chez la personne âgée. Par ailleurs, les pâtes fabriquées avec $100 \%$ de farine de légumineuses pourraient convenir aux personnes sensibles au gluten ou souffrant de la maladie cœliaque.

L'enrichissement en farine de légumineuses, s'il s'avère intéressant du point de vue de la composition nutritionnelle des pâtes, peut modifier leur structure et de ce fait également leurs propriétés nutritionnelles (effet matrice). Afin de comprendre cette relation, une étude approfondie de la structure des protéines a été réalisée à plusieurs échelles.

\subsection{L'enrichissement en légumineuse : répercussion sur la structure multi-échelle des spécialités pastières}

\section{A l'échelle moléculaire (figure 3):}

L'incorporation de quantités croissantes de fèverole (de 0 à 100\%) dans une pâte au blé s'est traduite sur les pâtes cuites, par une augmentation linéaire de la proportion de protéines liées par liaisons faibles, passant ainsi de 17 à 74\%, au détriment des liaisons fortes de type covalentes qui diminuaient de $83 \%$ dans une pâte de blé, à $26 \%$ dans une pâte $100 \%$ fèverole. Cette diminution de l'aptitude des protéines de fèverole à interagir par des ponts covalents, précédemment rapportée par Petitot, et al. (34), est liée à leur composition spécifique en acides 
aminés (jusqu'à 40\% plus pauvres en acides aminés soufrés que les protéines de blé, figure 2) susceptibles de former des ponts covalents de type disulfure entre les protéines.

\section{Figure 3 : Nature des interactions entre les protéines dans les pâtes enrichies en fèverole (de 0 à 100\%) séchées à basse température puis cuites.}

\section{A l'échelle microscopique (figure 4):}

L'analyse microscopique d'une coupe transversale d'une pâte de blé séchée à basse température et cuite montre de nombreux grains d'amidon compacts (en bleu) de forme allongée dans la région centrale de la pâte, entourés d'un réseau protéique très peu visible (en vert). La pâte $100 \%$ fèverole présente à l'inverse des grains d'amidon de forme ovale, moins nombreux, de taille plus importante et plus gonflée, et un réseau protéique plus visible conforme à leur teneur en protéine deux fois plus élevée que dans la pâte de blé. Dans la région extérieure, la pâte de blé présente des grains d'amidon très gonflés en comparaison avec la région interne de la pâte. Dans la pâte $100 \%$ fèverole, les grains d'amidons fusionnent à la surface de la pâte formant une sorte de phase continue à côté des protéines.

Figure 4 : Images microscopiques des pâtes 100\% blé dur (En haut de l'image) et $100 \%$ fèverole (en bas de l'image) $(35,36)$.

\subsection{L'enrichissement en légumineuse : répercussion sur les propriétés culinaires et rhéologiques des pâtes}

La modification de structure des pâtes par l'enrichissement en fèverole engendre une altération des propriétés texturales et culinaires des pâtes. La résilience des pâtes i.e. leur capacité à reprendre leur forme originale après compression diminue ainsi de 0,58 à 0,42 entre une pâte au blé dur et une pâte 100\% fèverole. Les pertes à la cuisson sont augmentées de 6,1 à 14,4 $\mathrm{g} / 100 \mathrm{~g}$ quand la quantité de légumineuse passe de 0 à 100\% (figure 5). Ces modifications de qualité culinaire et de propriétés rhéologiques en fonction du degré d'enrichissement en fèverole des pâtes sont linéaires et peuvent donc être prédites. L'incorporation de farine de fèverole, dépourvue de gluten, dilue le réseau protéique de la pâte et en affaiblit sa structure moléculaire expliquant, au moins partiellement, l'altération de ses qualités culinaires et rhéologiques. Le gluten, de par sa capacité à former des ponts covalents de type S-S, est en effet connu pour être un facteur majeur responsable des atouts culinaires et texturales des pâtes de blé $(37,38)$. De plus l'incorporation de farine de légumineuse dans la pâte contribue à en augmenter la teneur en fibres dans une proportion non négligeable $(11,7 \mathrm{~g} / 100 \mathrm{~g}$ dans une farine de fèverole contre $2,4 \mathrm{~g} / 100 \mathrm{~g}$ pour la semoule de blé, tableau 1). Selon Petitot et al. (2010) (13) et Padalino et al. $(13,39)$, l'inclusion de fibres dans la pâte pourrait favoriser une discontinuité de sa structure y compris à l'échelle microscopique, créant la formation de cracks affectant ainsi leurs propriétés texturales et culinaires.

Figure 5 : Pertes à la cuisson et résilience des pâtes séchées à basse température et cuites contenant un ratio «blé / fèverole » allant de «100/0 »

$$
\text { à « 0/100 » (36). }
$$




\section{Modulation de la structure de la pâte par le séchage}

Le séchage à haute température est utilisé dans les industries pastières pour réduire le temps consacré à cette étape du procédé (40). En parallèle, il présente l'avantage d'améliorer les propriétés rhéologiques et culinaires de pâtes au blé dur. L'utilisation de très hautes températures de séchage $\left(80-90^{\circ} \mathrm{C}\right)$ au lieu de hautes températures $\left(\sim 70^{\circ} \mathrm{C}\right)$ ou de basses températures $\left(55^{\circ} \mathrm{C}\right)$ réduit ainsi les pertes à la cuisson d'environ $10 \%$ et augmente la résilience des pâtes de blé de $6,6 \%(40,41)$. L'effet de la température de séchage des pâtes sur leurs qualités texturales et culinaires peut être lié à des modifications de la structure des pâtes qui pourraient se répercuter sur leurs propriétés nutritionnelles. En effet, il a été démontré que des températures de séchage élevées appliquées à une pâte de blé augmentent le phénomène d'agrégation des protéines par formation d'interactions hydrophobes et covalentes entre elles; cette structuration conduisant, notamment lorsque des températures de séchage supérieures à $85^{\circ} \mathrm{C}$ sont utilisées, à augmenter la part de protéines résistantes à la digestion in-vitro gastrique et intestinale (19).

\subsection{Le séchage THT appliquées aux spécialités pastières aux légumineuses: répercussion sur leur structure multi- échelle}

\section{A l'échelle moléculaire (figure 6)}

L'augmentation des températures de séchage des pâtes enrichies de 0 à $100 \%$ de fèverole change considérablement la structure du réseau protéique des pâtes sèches par l'augmentation jusqu'à 8 fois du taux d'interactions covalentes entre les protéines, au dépend des interactions faibles (36). Cette différence entre les pâtes séchées BT et THT s'atténue cependant après cuisson, notamment pour la pâte classique de blé dur comme le montre la figure 6A. Pour une pâte mixte contenant 35\% de fèverole (figure 6B), les différences de structure du réseau protéique liées au séchage sont conservées même après cuisson des pâtes avec une structuration plus forte du réseau protéique dans la pâte séchée THT cuite par rapport à la pâte BT cuite ; même si la pâte au blé demeure au final plus structurée que celle à la fèverole.

Figure 6 : Nature des interactions entre les protéines des pâtes cuites. A : pâtes de blé séchées soit à basse température $(100 \% \mathrm{BDBT})$ soit à très haute température $(100 \%$ BDTHT) ; $B$ : pâtes enrichies avec $35 \%$ de fèverole séchées soit à basse température (35\% FBT) soit à très haute température (35\% FTHT) $(42)$.

\section{A l'échelle microscopique (figure 7)}

Au niveau microscopique (figure 7), aucun effet majeur lié à l'augmentation des températures de séchage n'a été observé au centre d'une pâte $100 \%$ fèverole, si ce n'est une couleur légèrement plus foncée de l'amidon après coloration dans les pâtes séchées à très haute température, qui pourrait être attribuée à une gélatinisation plus limitée (3). La surface de la pâte 100\% FTHT présente des grains d'amidon moins fusionnés entre eux qu'une pâte 100\% FBT et mieux délimités par un réseau protéique plus intègre, probablement plus structuré étant donnée 
l'augmentation de la part des interactions covalentes en son sein observée à l'échelle moléculaire.

Figure 7 : Image microscopique d'une coupe transversale de pâtes $100 \%$ fèverole cuites.

En haut : séchage à basse température ; en bas : séchage à très haute température. $A$ gauche : centre de la pâte ; à droite : surface de la pâte (36).

\subsection{Le séchage THT appliquée aux spécialités pastières aux légumineuses: répercussion sur leur texture et leurs propriétés culinaires}

Le séchage à très haute température de spécialités pastières aux légumineuses atténue très efficacement l'effet négatif de l'enrichissement croissant en légumineuse sur leur résilience. En effet les pâtes séchées à THT ont une résilience similaire à celle des pâtes $100 \%$ blé quel que soit le taux d'incorporation de la légumineuse (tableau 3), contrairement aux pâtes séchées à basse température ou la résilience diminue de 0,58 à 0,42 entre une pâte au blé dur et une pâte $100 \%$ fèverole. Cependant, en ce qui concerne les propriétés culinaires, les pertes à la cuisson augmentent de $66 \%$ d'une pâte $100 \%$ blé à une pâte $100 \%$ fèverole. Néanmoins cette augmentation reste minime en comparaison avec les pâtes séchées à basse température (augmentation de 136\%). Une amélioration des pertes à la cuisson est observée lors de l'utilisation des très hautes températures de séchage vs basses températures, qui peut atteindre jusqu'à 36\% pour une pâte 100\% fèverole (tableau 3).

Tableau 3: Evolution de la résilience et des pertes à la cuisson suite à un séchage à très haute température (THT) vs basse température (BT) des pâtes

\begin{tabular}{ccccc}
\hline Pâtes & $\begin{array}{c}\text { Résilience pâtes } \\
\text { THT } \\
\text { Adimensionnelle }\end{array}$ & $\begin{array}{c}\text { Augmentation } \\
\text { résilience } \\
\text { THT/BT } \\
(\%)^{*}\end{array}$ & $\begin{array}{c}\text { Perte à la } \\
\text { cuisson } \\
\text { pâtes THT } \\
\text { (\% pâte sèche) }\end{array}$ & $\begin{array}{c}\text { Réduction Perte à la } \\
\text { cuisson } \\
\text { THT/BT } \\
(\%)^{*}\end{array}$ \\
\hline $100 \% \mathrm{BD}$ & $0,60 \pm 0,03$ & 4,76 & $5,54 \pm 0,73$ & $-9,10$ \\
$35 \% \mathrm{~F}$ & $0,57 \pm 0,01$ & 8,39 & $6,62 \pm 0,37$ & $-23,26$ \\
$70 \% \mathrm{~F}$ & $0,58 \pm 0,02$ & 20,47 & $8,35 \pm 0,43$ & $-25,82$ \\
$100 \% \mathrm{~F}$ & $0,61 \pm 0,01$ & 43,58 & $9,20 \pm 0,36$ & $-35,90$ \\
\hline
\end{tabular}

$100 \%$ BD, pâte de blé; $35 \% \mathrm{~F}$, pâtes enrichies avec 35\% de fèverole; $70 \% \mathrm{~F}$, pâtes enrichies avec $70 \%$ de fèverole; $100 \% \mathrm{~F}$, pâtes $100 \%$ fèverole ; BT, séchage à basse température; THT, séchage à très haute température.

Les valeurs sont exprimées en moyenne $\pm S D$.

*comparaison entre pâte séchée à très haute température et à basse température :

- Si la différence BT/THT est significative: la différence est calculée en utilisant la formule: $\frac{T H T-B T}{B T} \times 100$.

- Si différence non significative : Ns

3. L'enrichissement en légumineuses et l'augmentation des températures de séchage des pâtes modifient-ils la digestibilité des protéines et de l'amidon?

3.1. Digestibilité des protéines : 
L'incorporation de 35\% de farine de fèverole entraine une augmentation de $6 \%$ et de $11 \%$ de la digestibilité in-vitro des protéines, pour les pâtes séchées à respectivement BT et THT (Tableau 4). L'affaiblissement du réseau protéique, mis en évidence à l'échelle moléculaire, par l'augmentation du taux d'interactions non covalentes aux dépens des interactions covalentes, pourrait favoriser l'accessibilité des enzymes à leurs sites de coupures et améliorer la digestibilité des protéines in-vitro. Cette augmentation de la digestibilité des protéines au sein d'une pâte enrichie en farine de fèverole n'est plus retrouvée in-vivo chez le rat. En effet, la pâte enrichie à raison de $35 \%$ de farine de fèverole conserve une digestibilité vraie statistiquement identique à celle d'une pâte $100 \%$ blé isoprotéique quelles que soit les températures de séchage utilisées (28). A noter que la digestibilité est aussi légèrement inférieure à celle d'une protéine animale de référence, la caséine. Néanmoins, chez le rat, l'utilisation nette des protéines est de $75 \%$ et $55 \%$ plus élevée pour une pâte enrichie à $35 \%$ de fèverole comparativement à une pâte $100 \%$ blé isoprotéique, séchées respectivement à BT et THT. Ceci pourrait être directement lié à la composition en acides aminés indispensables plus équilibrée au sein de la pâte contenant de la farine de fèverole (figure 2). En effet, sa composition se rapproche de celle de la protéine animale de référence, la caséine, qui présente la meilleure rétention protéique probablement en lien avec sa composition plus riche en acides aminés indispensables, proche des besoins physiologiques du rat $(43,44)$.

Tableau 4. Digestibilité in-vitro et in-vivo des protéines et rétention protéique in-vivo

\begin{tabular}{cccc}
\hline Régimes & $\begin{array}{c}{ }^{\circ} \mathrm{H} \\
\text { (\% protéines totales) }\end{array}$ & $\begin{array}{c}\mathrm{DAV}^{* *} \\
\text { (\% azote ingéré) }\end{array}$ & $\begin{array}{c}\text { UNP** } \\
\text { (\% azote ingéré) }\end{array}$ \\
\hline $35 \%$ FBT & $44,6 \pm 1,0^{\mathrm{a}}$ & $98,3 \pm 1,3^{\mathrm{a}}$ & $76,4 \pm 2,5^{\mathrm{b}}$ \\
$35 \%$ FTHT & $46,3 \pm 1,5^{\mathrm{a}}$ & $97,2 \pm 1,2^{\mathrm{ab}}$ & $72,3 \pm 2,8^{\mathrm{b}}$ \\
$100 \%$ BDBT & $42,0 \pm 1,9 \mathrm{~b}$ & $98,5 \pm 0,6^{\mathrm{a}}$ & $43,7 \pm 1,9 \mathrm{a}$ \\
$100 \%$ BDTHT & $41,7 \pm 1,0^{\mathrm{b}}$ & $95,6 \pm 0,8^{\mathrm{b}}$ & $46,6 \pm 2,0^{\mathrm{a}}$ \\
Caséine & N/A & $101,9 \pm 0,5^{\mathrm{c}}$ & $83,8 \pm 3,3^{\mathrm{c}}$ \\
\hline
\end{tabular}

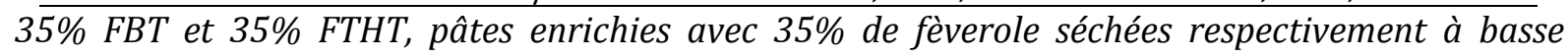
température et à très haute température; 100\% BDBT et 100\% BDTHT, pâtes de blé séchées respectivement à basse température et à très haute température.

${ }^{\circ} \mathrm{H}$, degré d'hydrolyse in-vitro ; DAV, digestibilité azotée vraie ; UNP, utilisation nette des protéines. $N / A$, non analysé.

* Degré d'hydrolyse in-vitro : les valeurs sont les moyennes $\pm S D$.

** Digestibilité azotée vraie et utilisation nette des protéines: les valeurs sont les moyennes \pm SEM (28).

Les moyennes avec des lettres différentes sur la même colonne sont significativement différentes.

Globalement, l'augmentation des températures de séchage (THT vs BT), n'entraine pas de modification de la digestibilité in-vitro des protéines, probablement du fait de la réduction des différences de structure moléculaire du réseau protéique entre les pâtes séchées à basse et à très haute température. In-vivo, un séchage THT engendre une diminution de la digestibilité vraie des protéines, significative seulement dans le cas de la pâte enrichie au gluten. Cette baisse de la digestibilité pourrait s'expliquer par la réduction de la biodisponibilité de certains acides aminés comme la lysine, déjà déficitaire dans une pâte $100 \%$ blé, et également engagés dans des réactions de Maillard engendrant des produits de Maillard comme les carboxyméthylysine. La production de ces composés augmente de $79 \%$ dans le cas des pâtes de blé dur enrichies en 
gluten et de $67 \%$ dans les pâtes 35\% fèverole (résultat non montré). Ces données expliqueraient la réduction plus prononcée de la digestibilité dans le cas de la pâte $100 \%$ blé par comparaison à la pâte enrichie avec $35 \%$ de farine de fèverole. Néanmoins, la baisse de la digestibilité des protéines engendrée par un séchage à très haute température n'engendre pas d'altération de l'utilisation des protéines issues d'une pâte au blé. Une utilisation nette des protéines deux fois plus importante était observée avec la consommation de la pâte enrichie en farine de féverole comparées à une pâte au blé quelles que soit les températures de séchage utilisées. A noter que dans ce dernier cas, l'utilisation protéique n'était seulement que 14\% inférieure à celle de la caséine.

\subsection{Digestibilité de l'amidon:}

L'incorporation de 35 ou 100\% de farine de fèverole dans une pâte augmente sa teneur en amidon résistant de 1.5 à 2 fois par comparaison à celle de la pâte de blé (Tableau 5). Le glucose disponible total diminue respectivement de 8 à 26\% dans la pâte 35\% FBT et 100\% FBT en comparaison avec la pâte de blé. Le glucose rapidement disponible (GRD) est identique entre une pâte de blé et une pâte 35\% FBT. La structure affaiblie du réseau protéique liée à la dilution du réseau de gluten par les protéines de légumineuses, ne favorise donc pas la digestibilité invitro de l'amidon. De plus, la pâte 100\% FBT présente même un GRD inférieur à celui d'une pâte de blé, et donc inversement un niveau de glucose lentement digestible (GLD) plus élevé. L'épaisseur plus importante du film protéique entourant les grains d'amidon dans les pâtes 100\% FBT associé à l'absence d'effet de l'affaiblissement de la structure du réseau protéique démontré sur la pâte $35 \% \mathrm{~F}$, pourrait expliquer ces résultats. De plus les grains d'amidon des légumineuses sont plus riches en amylose (30-37\%) (45) que ceux des céréales (18-33\%) (46). Un ratio amylose/amylopectine plus élevé favorise la rétrogradation de l'amidon formant une structure cristalline plus résistante aux enzymes digestives $(47,48)$. In-vivo, les pâtes aux légumineuses enrichies à 35\% de fèverole conservent un IG aussi bas qu'une pâte de blé (tableau $5)$.

Tableau 5 : Polysaccharides hors amidon, amidon résistant, glucose disponible, glucose rapidement disponible, et glucose lentement disponible dans la pâte cuite.

\begin{tabular}{|c|c|c|c|c|c|c|}
\hline Pâte & $\begin{array}{l}\text { Masse } \\
\text { sèche } \\
(\%)\end{array}$ & $\begin{array}{l}\text { Amidon } \\
\text { résistant } \\
\text { (g/100 mh) }\end{array}$ & $\begin{array}{l}\text { Glucose } \\
\text { disponible } \\
\text { (g/100 mh) }\end{array}$ & $\begin{array}{c}\text { GRD } \\
(\% \text { glc. } \\
\text { disponible) }\end{array}$ & $\begin{array}{l}\text { GLD } \\
\text { (\% glc. } \\
\text { disponible) }\end{array}$ & IG in-vivo \\
\hline 100\%BDBT & 32,8 & $0,58 \pm 0,01^{a}$ & $27,8 \pm 0,3^{a}$ & $67,0 \pm 0,7^{a}$ & $32,4 \pm 0,7^{a}$ & $52,3 \pm 7,0^{a}$ \\
\hline $35 \%$ FBT & 33,7 & $0,88 \pm 0,04 \mathrm{~b}$ & $25,6 \pm 0,3^{b}$ & $64,9 \pm 3,2^{\mathrm{a}}$ & $34,4 \pm 3,2^{a}$ & $41,9 \pm 5,7 a$ \\
\hline $35 \%$ FTHT & 33,3 & $0,95 \pm 0,04 \mathrm{~b}$ & $24,3 \pm 0,1^{c}$ & $53,0 \pm 0,4 b$ & $46,3 \pm 0,4 b$ & $49,4 \pm 6,8^{a}$ \\
\hline $100 \%$ FBT & 31,9 & $1,16 \pm 0,01$ & $20,5 \pm 0,1$ & $61,8 \pm 1,0$ & $36,4 \pm 1,0$ & $\mathrm{Nd}$ \\
\hline \multicolumn{7}{|c|}{$\begin{array}{l}\text { 35\% FBT et 35\% FTHT, pâtes enrichies avec } 35 \% \text { de fèverole séchées respectivement à basse } \\
\text { température et à très haute température; } 100 \% \text { BDBT pâtes de blé séchées à basse } \\
\text { température (29); } 100 \% \text { FBT pâte } 100 \% \text { fèverole séchée à basse température (35). }\end{array}$} \\
\hline \multicolumn{7}{|c|}{$\begin{array}{l}\text { GRD, glucose rapidement disponible; GLD, glucose lentement disponible; IG, indice glycémique ; } \\
\text { mh, masse humide. } \\
\text { Les valeurs sont les moyenne } \pm S D \text {, sauf pour l'indice glycémique (moyenne } \pm \text { SEM). }\end{array}$} \\
\hline
\end{tabular}


L'augmentation des températures de séchage dans le cas d'une pâte enrichie avec $35 \%$ de farine de fèverole (35 \% FTHT vs 35\% FBT) n'affecte pas l'amidon résistant, mais entraine une légère réduction du taux de glucose disponible de $5 \%$, et une diminution significative de $18.3 \%$ du niveau de GRD in-vitro contrebalancée par une augmentation du GLD de 35\%. Cette réduction du GRD ne s'est cependant pas traduite par une diminution significative de l'indice glycémique invivo quel que soit les températures de séchage. Néanmoins l'indice glycémique d'une pâte enrichie en fèverole et séchée à basse ou à très haute température reste de manière intéressante, statistiquement équivalent et aussi bas que celui d'une pâte au blé dur.

\section{A retenir}

Cette étude, conduite avec une approche transdisciplinaire a permis de démontrer qu'il est possible de modifier la structure des pâtes à toutes les échelles par son enrichissement en farines de légumineuses. Ces modifications de structure affectent la digestibilité de l'amidon et des protéines in-vitro. Ainsi, le niveau du glucose rapidement digestible diminue (notamment pour les pâtes $100 \%$ fèverole) en partie en lien avec l'épaississement du réseau protéique de la pâte, alors que l'hydrolyse des protéines in-vitro augmente, en relation avec l'affaiblissement de la force des interactions entre les protéines au sein de ce réseau. In-vivo, aucun effet de la structure sur l'indice glycémique ou la digestibilité des pâtes enrichies avec $35 \%$ de fèverole n'a été noté. Cependant, la rétention protéique de cette pâte mixte fèverole/blé est deux fois plus importante que dans une pâte de blé et proche de celle obtenue pour une protéine animale de référence (la caséine), faisant de cet aliment mixte une option très intéressante au niveau nutritionnel notamment pour la population vieillissante.

Le séchage modifie la structure de la pâte mais dans une moindre mesure comparé aux effets obtenus par un changement de sa formulation. Son effet est plus important dans les pâtes enrichies en fèverole que dans une pâte de blé, et ce notamment aux échelles moléculaire et macroscopique. Ces modifications de structure liée au séchage abaissent le glucose rapidement digestible in-vitro sans effet sur l'indice glycémique in-vivo. De même, aucun effet du séchage n'a été observé pour l'hydrolyse des protéines in-vitro. In-vivo l'augmentation des températures de séchage affecte seulement la digestibilité des protéines de la pâte de blé, en relation avec la baisse de la biodisponibilité de certaines acides aminés indispensables comme la lysine. Quel que soit ses températures de séchage, la pâte enrichie en fèverole présente une quantité de lysine supérieure à celle d'une pâte classique de blé. Un séchage à très haute température des pâtes enrichies en légumineuses permet donc d'améliorer leurs propriétés culinaires et rhéologiques sans affecter leurs propriétés nutritionnelles.

La modulation des propriétés nutritionnelles des pâtes par modification de leur structure pourraient être amplifiée dans le cas d'un enrichissement en légumineuse plus important des pâtes (i.e. entre 50 et $100 \%$ ). 


\section{Résumé}

Ce travail s'intéresse à l'évaluation simultanée de l'effet de l'enrichissement en farine de légumineuse (notamment de fèverole, à un taux allant de 0 à $100 \%$ ) et de l'augmentation des températures de séchage $\left(55^{\circ} \mathrm{C}\right.$-basse température, $\mathrm{BT} / 90^{\circ} \mathrm{C}$-très haute température, THT) de pâtes sur la modification de leur structure et plus particulièrement celle de leur réseau protéique. Cette modification de structure est étudiée à plusieurs échelles (macroscopique, microscopique et supramoléculaire). Les répercussions sur la digestibilité in-vitro de l'amidon et des protéines sont déterminées. La variation du métabolisme protéique et de l'indice glycémique engendrée par la modification de la composition et du procédé de fabrication des pâtes est évaluée sur modèles rats pour le métabolisme des protéines, et sur volontaires humains pour l'indice glycémique.

Figure 8 : Schéma général et objectif de l'étude

\section{Mots clés}

Effet matrice, qualités nutritionnelles, fève, blé dur, acides aminés indispensables. 


\begin{abstract}
This study evaluated the simultaneous effect on pasta structure of the enrichment in faba bean flour (from 0 to $100 \%$ ) and the use of low temperature drying (LT, $55^{\circ} \mathrm{C}$ ) instead of very high temperature drying $\left(\mathrm{VHT}, 90^{\circ} \mathrm{C}\right)$. The structural changes induced were studied at different scales (from the macroscopic to the molecular scales) with a focus on the pasta protein matrix. Their repercussions on the in-vitro digestibility of starch and proteins were determined. In addition, the variation in protein metabolism and glycemic index caused by the modification of the pasta formulation and process was evaluated on rat models for protein metabolism, and on human volunteers for the glycemic index.
\end{abstract}

\title{
Key words:
}

Food matrix, Nutritional quality, Faba bean, Durum wheat, Essential amino acids. 


\section{Remerciements}

Les auteurs remercient J. Bonicel, T-M. Lasserre, D. Cassan et S. Barbe (INRA Montpellier, France) pour leur assistance technique dans la production et l'analyse des pâtes, C. Barron pour l'aide à la réalisation des techniques microscopiques, M.-H. Morel pour les discussions sur la structure des matrices, G. Conéjéro (INRA, Montpellier, France) pour les facilités d'accès à la Plate-forme d'Histocytologie et d'Imagerie cellulaire Végétale (PHIV, Montpellier), A. Avignon (CHU Montpellier) pour l'accès au service des maladies métaboliques et pour son aide au montage de l'étude clinique sur l'IG in-vivo, C. Basurko (CIC-EC des Antilles et de la Guyane, Centre hospitalier de l'Ouest Guyanais), pour l'aide à la rédaction du protocole clinique, T. Sutra (CHU Montpellier) pour sa participation au déroulement des essais cliniques sur l'IG in-vivo, M. Lubat pour l'échantillonnage du sang, M. Depetris et N. Molinari (JRU IATE-Montpellier SupAgro et CHU NÎmes), pour l'aide dans les analyses statistiques de l'étude in-vivo de la digestibilité du glucose, J. Salles, A. Berry, C. Giraudet, P. Denis, V. Patrac, C. Guillet, Y. Boirie (INRA, UNH, Clermont-Ferrand, France) pour l'aide à la réalisation de l'expérimentation animale in-vivo, $\mathrm{F}$. Tessier, A. Guilbaud et M. Howsam, (Université de Lille, Lille, France) pour l'analyse du carboxymethy-lysine dans les pâtes. Les auteurs remercient GEMEF Industries (Aix-enProvence, France), Panzani (Panzani, Marseille, France) et Syral (Aalst, Belgique), respectivement pour avoir fourni la farine de fèverole, la semoule de blé dur et le gluten de blé tendre.

\section{Financements}

Les résultats présentés ici ont été obtenus dans le cadre des projets Vegage («Vitesse de digestion et intérêt nutritionnel des sources protéiques végétales sur la rétention azotée et le métabolisme protéique au cours du vieillissement » financé par l'Institut Carnot Qualiment et par la Région Auvergne) et Pastaleg in-vivo (financé par le prix Chercheur d'Avenir 2009 Région Languedoc-Roussillon et Montpellier SupAgro). L'étude de l'indice glycémique in-vivo a été financée par le prix Chercheur d'Avenir 2009 (Région Languedoc-Roussillon).

\section{Conflit d'intérêt :}

Aucun conflit d'intérêt à déclarer. 


\section{Références bibliographiques}

1. Passion Céréales, Des chiffres et des céréales - édition 2017.

2. CFSI-SIFPAF, Syndicat des industriels fabricants de pâtes alimentaires de France - Comité Français de la semoulerie industrielle. La filière Semoule, Pâtes et Couscous. Chiffres clés 2017. www.semouleetpates.org.

3. Cunin C, Handschin S, Walther P, Escher F, Structural-changes of starch during cooking of durum-wheat pasta. Lebenson Wiss Technol 1995; 28, 323-328.

4. Pagani M A, Gallant D J, Bouchet B, Resmini P, Ultrastructure of cooked spaghetti. Food Microstructure 1986; 5, 111-129.

5. Granfeldt Y, Bjorck I, Glycemic response to starch in pasta - a study of mechanisms of limited enzyme availability. J Cereal Sci 1991; 14, 47-61.

6. Colonna P, Barry J L, Cloarec D, Bornet F, Gouilloud S, Galmiche J P, Enzymic susceptibility of starch from pasta. J Cereal Sci 1990; 11, 59-70.

7. Foster-Powell K, Holt S H A, Brand-Miller J C, International table of glycemic index and glycemic load values: 2002. Am J Clin Nutr 2002; 76, 5-56.

8. Jenkins D J A, Kendall C W C, Augustin L S A, Franceschi S, Hamidi M, Marchie A, et al., Glycemic index: overview of implications in health and disease. Am J Clin Nutr 2002; 76, 266S-273S.

9. Barclay A W, Petocz P, McMillan-Price J, Flood V M, Prvan T, Mitchell P, et al., Glycemic index, glycemic load, and chronic disease risk--a meta-analysis of observational studies. Am J Clin Nutr 2008; 87, 627-37.

10. Brand-Miller J C, Holt S H A, Pawlak D B, McMillan J, Glycemic index and obesity. Am J Clin Nutr 2002; 76, 281S-285S.

11. Abdel-Aal E S M, Hucl P, Amino acid composition and in vitro protein digestibility of selected ancient wheats and their end products. J Food Compost Anal 2002; 15, 737-747.

12. Duranti $M$, Grain legume proteins and nutraceutical properties. Fitoterapia 2006; 77, 67-82.

13. Petitot M, Boyer L, Minier C, Micard V, Fortification of pasta with split pea and faba bean flours: Pasta processing and quality evaluation. Food Res Int 2010; 43, 634-641.

14. Gimenez M A, Drago S R, De Greef D, Gonzalez R J, Lobo M O, Samman N C, Rheological, functional and nutritional properties of wheat/broad bean (Vicia faba) flour blends for pasta formulation. Food Chem 2012; 134, 200-206.

15. Wood J A, Texture, processing and organoleptic properties of chickpea-fortified spaghetti with insights to the underlying mechanisms of traditional durum pasta quality. J Cereal Sci 2009; 49, 128-133.

16. Rosa-Sibakov N, Heinio R-L, Cassan D, Holopainen-Mantila U, Micard V, Lantto R, et al., Effect of bioprocessing and fractionation on the structural, textural and sensory properties of gluten-free faba bean pasta. Lebenson Wiss Technol 2016; 67, 27-36.

17. Jayasena V, Nasar-Abbas S M, Development and quality evaluation of high-protein and highdietary-fiber pasta using lupin flour. J. Texture Stud 2012; 43, 153-163.

18. Rajiv J, Milind, Suresh D S, Aashitosh A I, Venkateswara Rao G, Effect of green gram semolina ( Phaseolus aureus) on the rheology, nutrition, microstructure and quality characteristics of highprotein pasta. J Food Process Preserv 2014; 38, 1965-1972.

19. De Zorzi M, Curioni A, Simonato B, Giannattasio M, Pasini G, Effect of pasta drying temperature on gastrointestinal digestibility and allergenicity of durum wheat proteins. Food Chem 2007; 104, 353-363.

20. Petitot M, Micard V, Legume-Fortified Pasta. Impact of Drying and Precooking Treatments on Pasta Structure and Inherent In Vitro Starch Digestibility. Food Biophysics 2010; 5, 309-320.

21. Arrêté du 25 juillet 1986 relatif à la méthode officielle d'analyse pour la détermination de la teneur en fibres alimentaires totales des produits au son.

22. Laleg K, Cassan D, Abecassis J, Micard V Procédé de fabrication de pâte destinée a I'alimentation humaine et/ou animale comprenant au moins 35\% de legumineuse. Institut national 
de la recherche agronomique (INRA) - centre international d'etudes superieures en sciences agronomiques (SupAgro). France. WO2016097328 A1. 23 juin 2016. 2016.

23. Morel M H, Dehlon P, Autran J C, Leygue J P, Bar-L'Helgouac'h C, Effects of temperature, sonication time, and power settings on size distribution and extractability of total wheat flour proteins as determined by size-exclusion high-performance liquid chromatography. Cereal Chem 2000; 77, 685-691.

24. Pasini G, Simonato B, Giannattasio M, Peruffo A D B, Curioni A, Modifications of wheat flour proteins during in vitro digestion of bread dough, crumb, and crust: An electrophoretic and immunological study. J Agric Food Chem 2001; 49, 2254-2261.

25. Prochazkova S, Varum K M, Ostgaard K, Quantitative determination of chitosans by ninhydrin. Carbohydrate Polymers 1999; 38, 115-122.

26. Englyst K N, Englyst H N, Hudson G J, Cole T J, Cummings J H, Rapidly available glucose in foods: an in vitro measurement that reflects the glycemic response. Am J Clin Nutr 1999; 69, 448454.

27. Arrêté du 8 septembre 1977 relatif aux méthodes officielles d'analyse des produits diététiques et de régime. Article 2 : Détermination de la teneur en lipides totaux.

28. Laleg K, Salles J, Berry A, Giraudet C, Patrac V, Guillet C, et al., Nutritional evaluation of mixed wheat-faba bean pasta in growing rats: Impact of protein source and drying temperature on protein digestibility and retention. Br J Nutr Accepted 20/11/2018.

29. Greffeuille V, Marsset-Baglieri A, Molinari N, Cassan D, Sutra T, Avignon A, et al., Enrichment of pasta with faba bean does not impact glycemic or insulin response but can enhance satiety feeling and digestive comfort when dried at very high temperature. Food Funct 2015; 6, 2996-3005.

30. ANSES, Apport en protéines : consommation, qualité, besoins et recommandations. Synthèse du rapport de l'Afssa. MAISONS-ALFORT, France. www.afssa.fr. 2007, 64p.

31. Anthony J C, Yoshizawa F, Anthony T G, Vary T C, Jefferson L S, Kimball S R, Leucine stimulates translation initiation in skeletal muscle of postabsorptive rats via a rapamycin-sensitive pathway. J Nutr 2000; 130, 2413-2419.

32. Dardevet D, Sornet C, Bayle G, Prugnaud J, Pouyet C, Grizard J, Postprandial stimulation of muscle protein synthesis in old rats can be restored by a leucine-supplemented meal. J Nutr 2002; 132, 95-100.

33. Rieu I, Balage M, Sornet C, Giraudet C, Pujos E, Grizard J, et al., Leucine supplementation improves muscle protein synthesis in elderly men independently of hyperaminoacidaemia. J Physiol 2006; 575, 305-315.

34. Petitot M, Barron C, Morel M-H, Micard V, Impact of legume flour addition on pasta structure: consequences on its in vitro starch digestibility. Food Biophys 2010; 5, 284-299.

35. Laleg K, Cassan D, Barron C, Prabhasankar P, Micard V, Structural, Culinary, Nutritional and Anti-Nutritional Properties of High Protein, Gluten Free, 100\% Legume Pasta. PLoS ONE 2016; 11.

36. Laleg K, Barron C, Cordelle S, Schlich P, Walrand S, Micard V, How the structure, nutritional and sensory attributes of pasta made from legume flour is affected by the proportion of legume protein. Lwt-Food Science and Technology 2017; 79, 471-478.

37. Matsuo R R, Irvine G N, Effect of gluten on cooking quality of spaghetti. Cereal Chem 1970; 47, 173-180.

38. Matsuo R R, Bradley J W, Irvine G N, Effect of protein content on the cooking quality of spaghetti. Cereal Chem 1972; 49, 707-711.

39. Padalino L, Mastromatteo M, Lecce L, Spinelli S, Conto F, Del Nobile M A, Chemical composition, sensory and cooking quality evaluation of durum wheat spaghetti enriched with pea flour. Int J Food Sci Technol 2014; 49, 1544-1556.

40. Guler S, Koksel H, Ng P K W, Effects of industrial pasta drying temperatures on starch properties and pasta quality. Food Res Int 2002; 35, 421-427.

41. Petitot M, Brossard C, Barron C, Larre C, Morel M H, Micard V, Modification of pasta structure induced by high drying temperatures. Effects on the in vitro digestibility of protein and 
starch fractions and the potential allergenicity of protein hydrolysates. Food Chem 2009; 116, 401412.

42. Laleg K, Barron C, Sante-Lhoutellier V, Walrand S, Micard V, Protein enriched pasta: structure and digestibility of its protein network. Food Funct. 2016; 7, 1196-1207.

43. National Research Council, Nutrient Requirements of Laboratory Animals: Fourth Revised Edition. pp. 22-27. National Academy of Science, Washington (DC). 1995.

44. Hoebler C, Karinthi A, Devaux M F, Guillon F, Gallant D J G, Bouchet B, et al., Physical and chemical transformations of cereal food during oral digestion in human subjects. Br J Nutr 1998; 80, 429-436.

45. Hoover R, Sosulski F, Studies On The Functional-Characteristics And Digestibility Of Starches From Phaseolus-Vulgaris Biotypes. Starke 1985; 37, 181-191.

46. Buleon A, Colonna P, Planchot V, Ball S, Starch granules: structure and biosynthesis. Int. J. Biol. Macromol 1998; 23, 85-112.

47. Brijesh T, Narpinder S, Pulse chemistry and technology. 1st ed. Cambridge: RCSPublishing; 2012.

48. Petitot M, Abecassis J, Micard V, Structuring of pasta components during processing: impact on starch and protein digestibility and allergenicity. Trends Food Sci Technol 2009; 20, 521-532.

\section{Légende des figures :}

Figure 1: Diagrammes de séchage des pâtes. BT: Basse température, et THT: Très haute température.

HR\% : Humidité relative

Figure 2: Evolution de la teneur en protéines et du score en acides aminés indispensables d'une pâte sèche en fonction de son enrichissement en farine de fèverole.

Figure 3 : Nature des interactions entre les protéines dans les pâtes enrichies en fèverole (de 0 à $100 \%$ ) séchées à basse température puis cuites

Figure 4 : Images microscopiques des pâtes 100\% blé dur (En haut de l'image) et $100 \%$ fèverole (en bas de l'image).

Figure 5 : Pertes à la cuisson et résilience des pâtes séchées à basse température et cuites contenant un ratio « blé / fèverole » allant de « 100/0 » à « 0/100 ».

Figure 6 : Nature des interactions entre les protéines des pâtes cuites. A : pâtes de blé séchées soit à basse température $(100 \%$ BDBT) soit à très haute température $(100 \%$ BDTHT) ; $\mathrm{B}$ : pâtes enrichies avec $35 \%$ de fèverole séchées soit à basse température $(35 \% \mathrm{FBT})$ soit à très haute température (35\% FTHT).

Figure 7 : Image microscopique d'une coupe transversale de pâtes $100 \%$ fèverole cuites. En haut : séchage à basse température; en bas : séchage à très haute température. A gauche : centre de la pâte ; à droite : surface de la pâte.

Figure 8 : Schéma général et objectif de l'étude. 
BT $55^{\circ} \mathrm{C}-16 \mathrm{~h}$ HR\%: 70-90\%

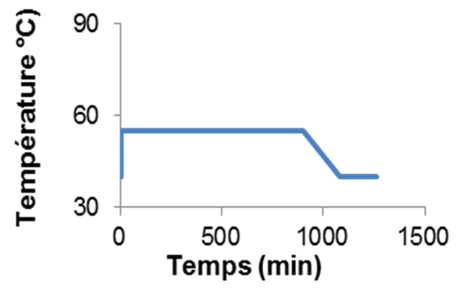

\section{THT $90^{\circ} \mathrm{C}-6 \mathrm{~h}$}

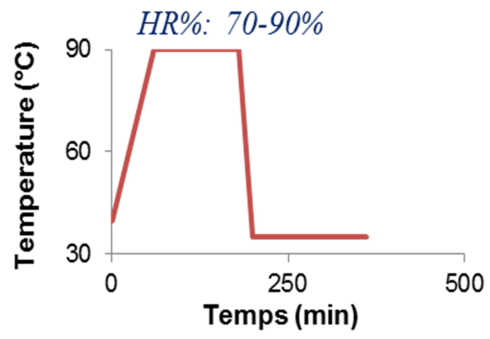




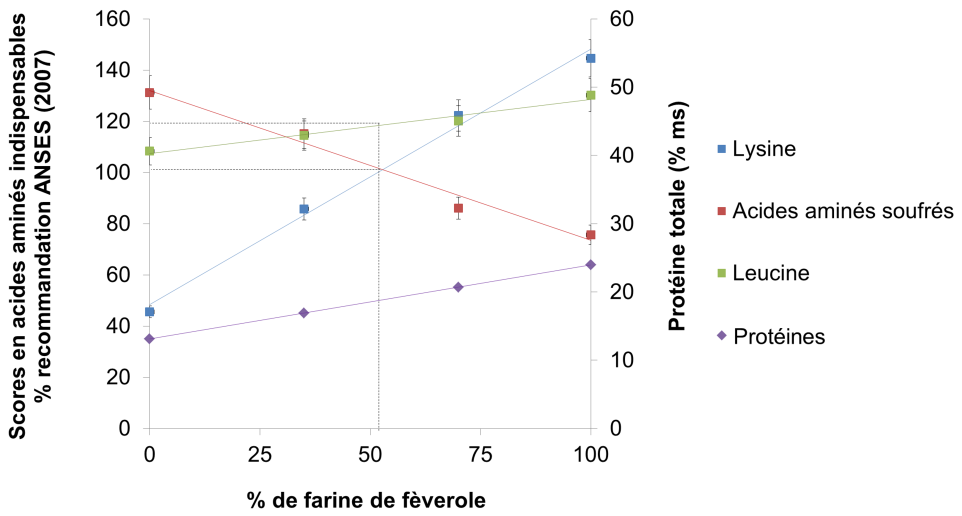




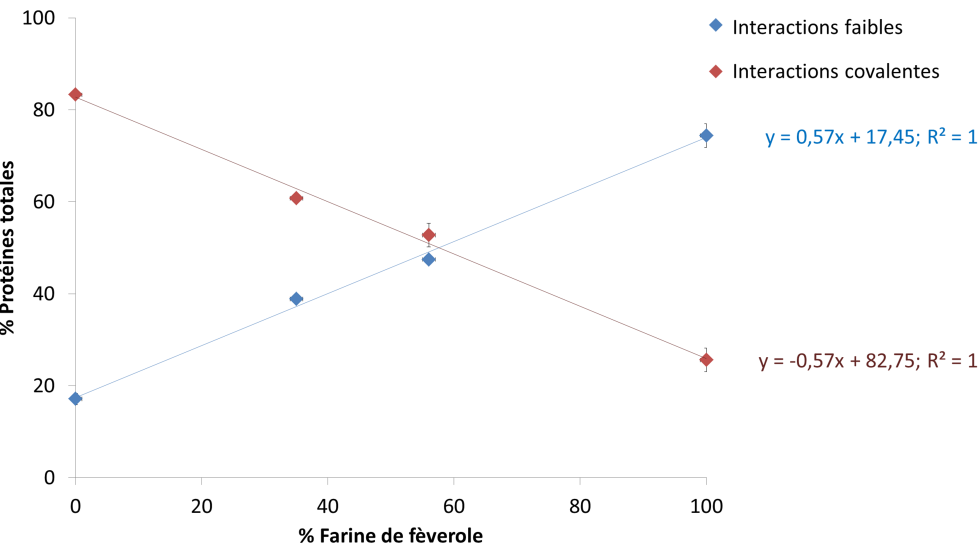




\section{$100 \% \mathrm{BD}-$ centre}

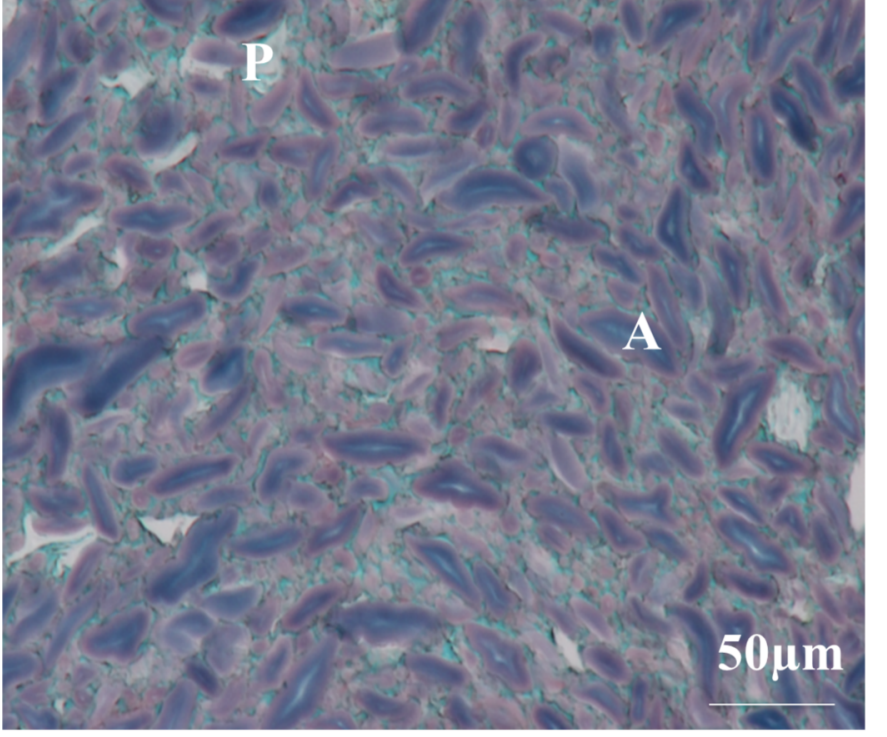

\section{$100 \%$ F - centre}

$50 \mu \mathrm{m}$
$100 \%$ BD - surface

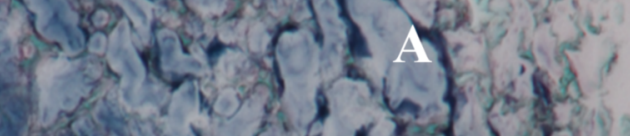

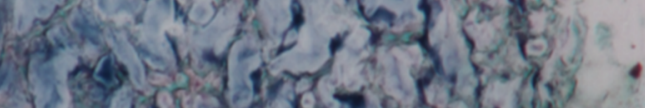

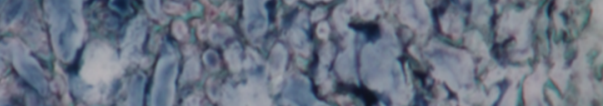

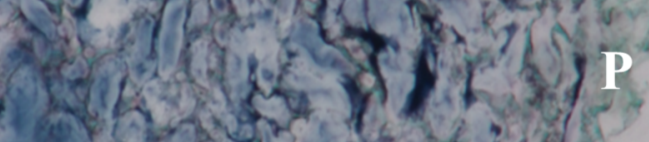

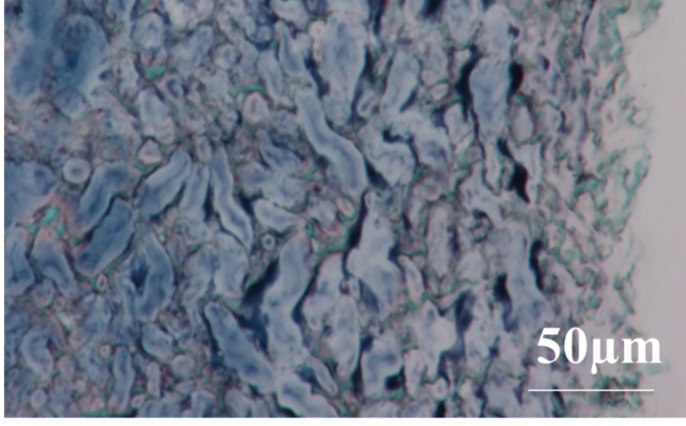

\section{$100 \% \mathrm{~F}$-surface}

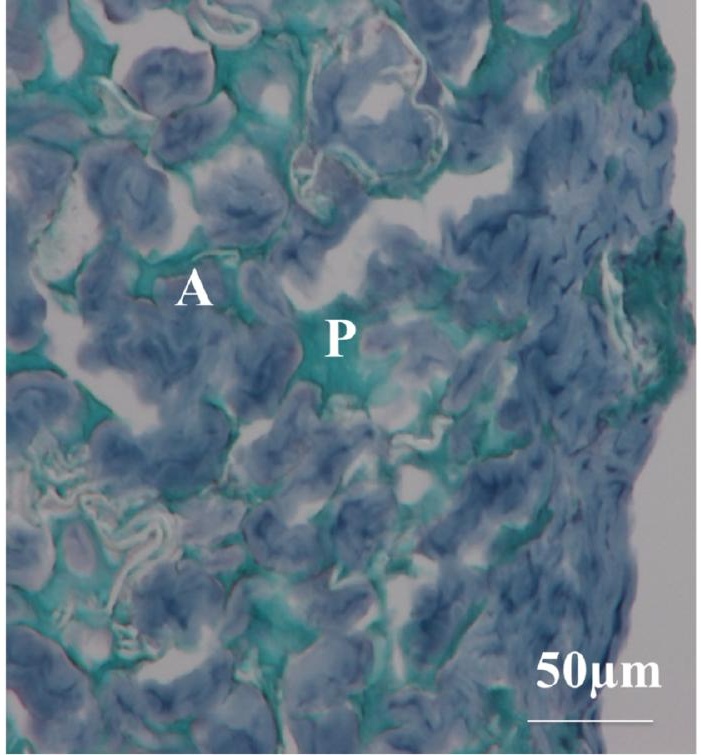




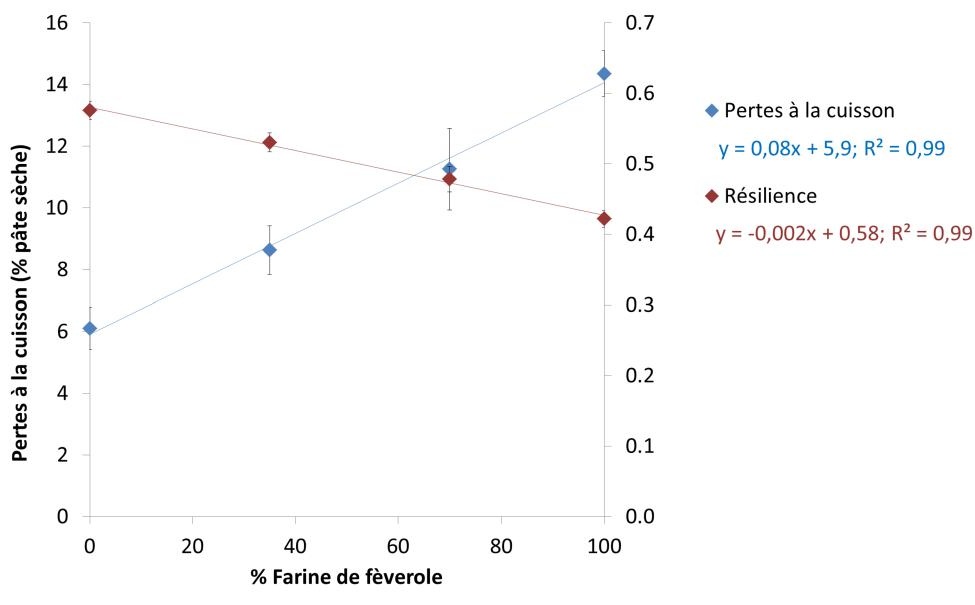


A 100

y $80 \square 100 \%$ BDBT

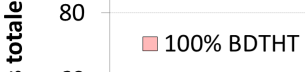

๖ 60

40

20

0

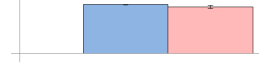

Interactions faibles

Interactions covalentes

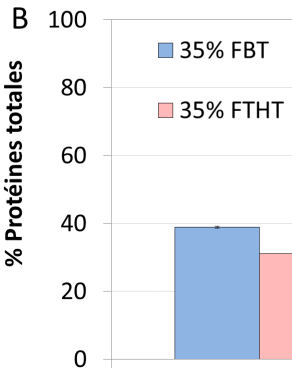

Interactions faibles

Interactions covalentes 


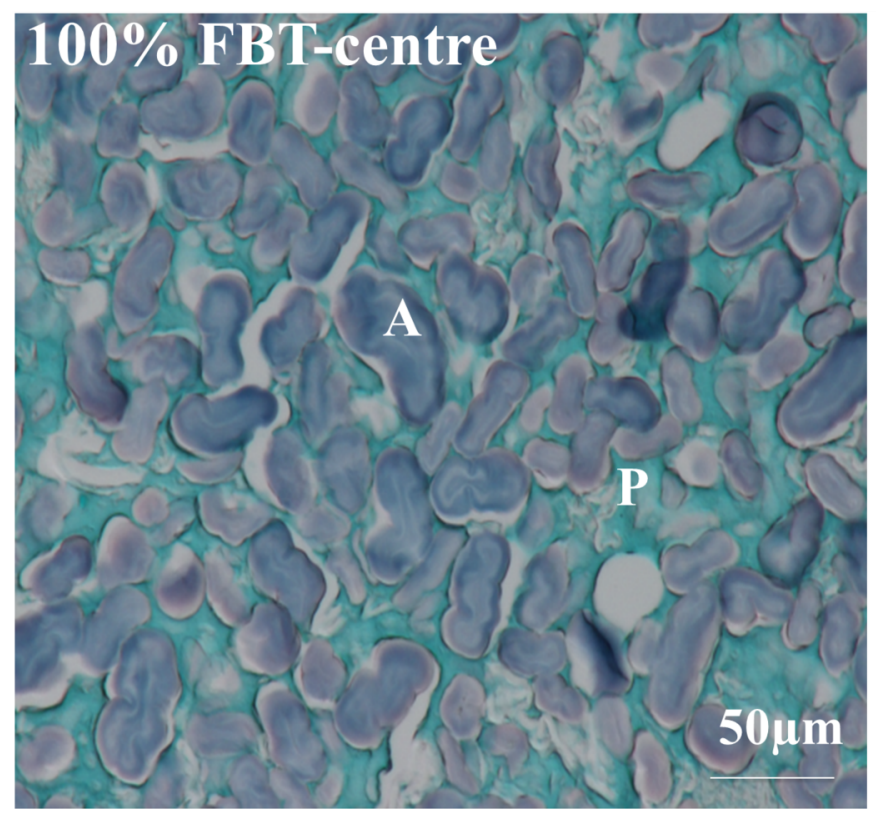

\section{$100 \%$ EBT- surface}

$100 \%$ FTHT-centre

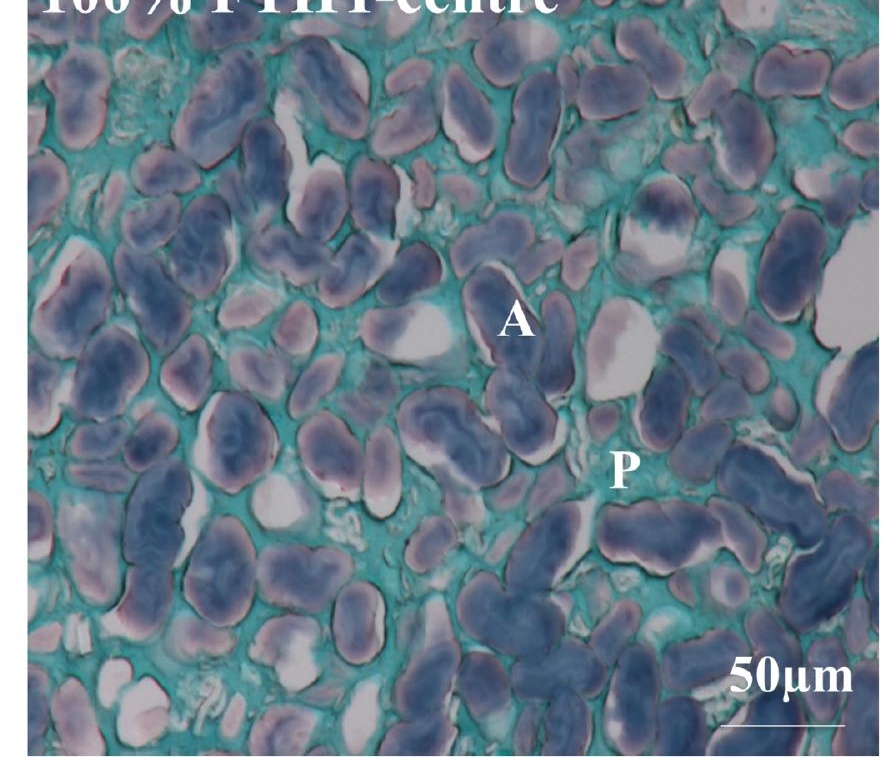

$100 \%$ FTHT-surface

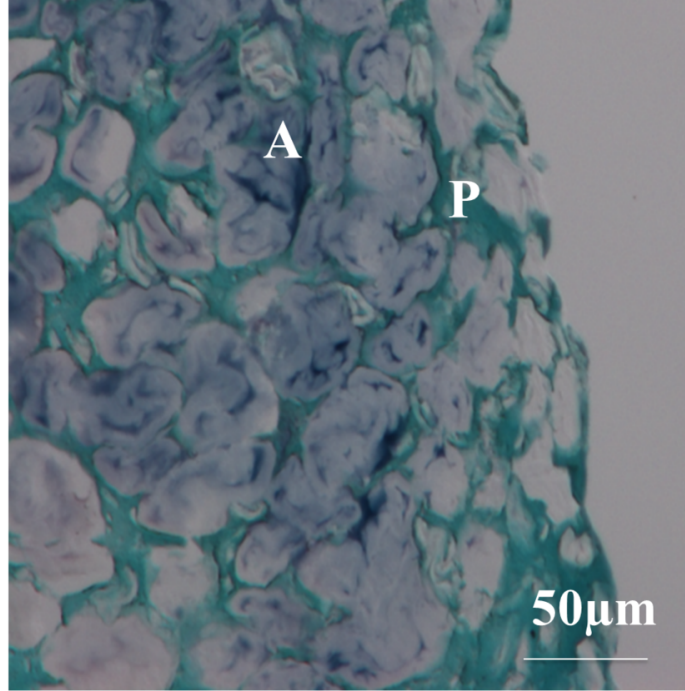




\section{Effet de la} formulation

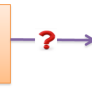

0-100\% fève

\section{Structure multi-échelle} de la pâte
Effet du procédé

Séchage: $55^{\circ} \mathrm{C} / 90^{\circ} \mathrm{C}$
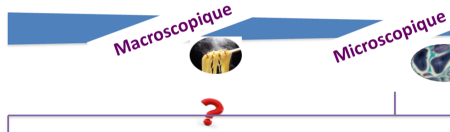

Amidon

Digestibilité in vitro Hiilit

Indice glycémique in vivo supramoléculaire

?

\section{Protéines}

Digestibilité in vitro et in vivo

$$
\text { ब्रिक्ष }
$$

Métabolisme protéique 